\title{
Consumer health 2.0 in Canada: a descriptive analysis of the use of Web 2.0 technologies on Canadian consumer health information websites
}

\author{
Christine Marton
}

\begin{abstract}
An examination of the top 10 consumer health information (CHI) websites in Canada revealed that while all of these CHI websites provide extensive and well-organized content, hypertext links, static images, and a site search engine, their adoption of Web 2.0 technologies is generally limited to well-known technologies, such as Facebook and Twitter, or is nonexistent. Furthermore, CHI websites that fail to integrate links to Web 2.0 technologies into the main navigation bar on the homepage make the links less visible to site visitors.
\end{abstract}

\section{Introduction}

Many reputable consumer health information (CHI) websites were developed by healthcare institutions, diseasespecific not-for-profit organizations, professional associations, government health ministries, and telecommunication and broadcasting companies in the late 1990s and early 2000s. These sites are authored by clinicians and medical writers who control the publication of content. Examples of established health portal sites include MedlinePlus (http://www. nlm.nih.gov/medlineplus/) and WebMD (http://www.webmd. $\mathrm{com} /$ ) in the United States, and the Canadian Health Network (no longer in existence), Bell Sympatico's Healthy Way (no longer in existence); and MedBroadcast (http://www. medbroadcast.com/) in Canada. Clearly, these types of CHI websites function primarily as distributors of textbook-style biomedical information. The content is overwhelmingly static text with a limited selection of images of organs and organ systems; a few decision making tools, such as body mass indicator calculators; and optionally, one or more forms of computer-mediated communication, such as discussion forums. While these sites do not exemplify the latest trends in Web technology, they do meet the fundamental needs of those seeking health information: the need for factual biomedical information about diseases and their causes, symptomology, diagnostic tests, treatment options, and prognosis.

In the early 1990s, the Internet-based hypertext system known as the World Wide Web (WWW) was developed. Soon after, the first graphical Web browsers for accessing the WWW became widely available [1]. In this decade, the next stage of Web development has been characterized by the creation of many interactive technologies, collectively referred to as Web 2.0 or the Social Web [2]. Social websites offer many opportunities for creating user-generated content on any topic of interest, around which an engaged community of interest can arise and grow, becoming a world-wide membership. Web 2.0 technologies facilitate information sharing and the ready use of multimedia elements, such as photos; audio clips; videos, often of personal activities, experiences, and events; as well as mixing these technologies and creating so-called mash-ups. Anyone can create content using readily available suites of online tools; sophisticated computing skills are not required.

Popular Web 2.0 technologies include blogs (Web diaries with entries in reverse-chronological order and comments from visitors); micro-blogging utilities such as Twitter; social networking sites such as Facebook, MySpace, and Foursquare, which feature user profiles, photos, contacts, and blog entries with comments from friends; YouTube, a video-sharing site featuring user-generated video content created by individuals as well as organizations and media corporations; Really Simple Syndication (RSS) feeds that enable users to subscribe to websites to obtain new content and view it through an RSS feeder, instead of visiting websites individually to scan for updater; podcasts, digital audio or video files that are released episodically and can be downloaded automatically to the user's computer and used offline; social bookmarking, the online storage, management, and searching of bookmarks on the Web; and folksonomy or social tagging, the addition of metadata to shared Web content.

The personalized approach to $\mathrm{CHI}$ on the Web, characteristic of Web 2.0 websites developed by individuals (and groups) with specific illnesses, presents an interesting contrast to the standardized biomedical textual content provided by conventional CHI websites. By comparison, these established $\mathrm{CHI}$ sites are late adopters of Web 2.0 technologies. In this

C. Marton. Faculty of Information, University of Toronto, 140 St. George Street, Toronto, ON M5S 3G6, Canada (e-mail: christine. marton@utoronto.ca). 
paper, the prevalence of Web 2.0 technologies on the foremost CHI websites in Canada is investigated.

\section{Methods}

In 2010, the Consumer Health Information Providers Interest Group of the Canadian Health Libraries Association published a new version of its "Top 10 Canadian Consumer Health Websites" [3]. These reputable CHI websites cover specific health topics, e.g., cancer, mental health, sexuality, or a distinct population demographic, e.g., women, children, or Francophones. The list is presented below.

About Kids Health
Caring for Kids
Canadian Cancer Society
Canadian Safety Council
Dietitians of Canada
Heart and Stroke Foundation
Here to Help
Sexualityandu.ca
PasseportSanté
Women's Health Matters

aboutkidshealth.ca caringforkids.cps.ca cancer.ca safety-council.org dietitians.ca

heartandstroke.ca heretohelp.ca sexualityandu.ca passeportsante.net womenshealthmatters.ca

As well, honourable mentions were bestowed on the following Canadian CHI websites:

$$
\begin{aligned}
& \text { Canadian AIDS Treatment } \\
& \text { Information Exchange } \\
& \text { Canadian Centre for Occupational } \\
& \text { Health and Safety } \\
& \text { Canadian Women's Health Network } \\
& \text { Canadian Virtual Hospice } \\
& \text { HealthLinkBC } \\
& \text { Public Health Agency of Canada }
\end{aligned}
$$

catie.ca
ccohs.ca
cwhn.ca
virtualhospice.ca
healthlinkbc.ca
phac-aspc.gc.ca

Visits to the 10 top-rated Canadian CHI websites, and inspections of their Web 2.0 technologies, were conducted on 25 November 2010. A descriptive analysis of the current use of Web 2.0 technologies on each of these reputable Canadian CHI websites is presented next.

\section{Results}

\section{The Canadian Cancer Society}

The Canadian Cancer Society (CCS) (http://www.cancer. ca) is the national not-for-profit organization of communitybased volunteers in Canada dedicated to eradicating cancer and improving the quality of life of people living with cancer. The CCS website is primarily organized by geographic region (national and provincial) and provides extensive textual content centred in each webpage, with the sides of each webpage acting as navigation tools. Web 2.0 technologies are detailed on a separate webpage linked from the homepage; Other Ways to Stay Connected [4]. Although this link is not integrated into the top menu bar of the CCS website homepage, its large size renders its location on the centreright side of the homepage visible to site visitors.

The CCS Twitter feed [5] has a total of 1151 tweets since 6 January 2009, with an average of one or two tweets per day. Topics include new cancer research, vitamin D supplements, contraband tobacco, the financial burden of care-giving, the Ontario Health Study, and CCS events, services, and lottery. It has 4804 followers and is following 434 individuals and groups, among them are NDP leader Jack Layton (JackLayton), Relay For Life Toronto (RelayForLifeTO), and Community Living Ontario (CLOntario).

The CCS Facebook site [6] has many posts on its wall, both from the CCS itself, as well as from cancer patients and survivors and cancer groups. Over the past two months, there have been approximately 100 posts, many with comments, indicating considerable involvement from the cancer community. As well, the Facebook site has eight CCS photo albums and 136 photos posted by others; three CCS videos and two videos posted by others; and eight events. The content and interactivity on the CCS Facebook site is impressive.

Furthermore, the CCS has a YouTube channel [7] with 19918 channel views; 224380 total upload views, and 591 subscribers; an RSS feed [8] with comprehensive instructions on the use of RSS feeds [9]; and also offers personalization through iGoogle [10], which enables the clipping of content of personal interest from the Web.

\section{PassportSanté}

PasseportSanté (http://www.passeportsante.net/Fr/Accueil/ Accueil/Accueil.aspx) is a Francophone CHI website, which is affiliated with the Lucie et André Chagnon Foundation, a not-for-profit organization in Quebec dedicated to health promotion and disease prevention, and published by Totalmédia inc. It has over 2 million site visitors per month from all over the world. This website features extensive informational content and well-designed images and navigation tools.

PasseportSanté offers an extensive number of audio clips and videos on a range of health topics and features several types of Web 2.0 technologies, including: blogs authored by health professionals [11], which can be received as RSS feeds [12]; a Facebook site [13]; and an established Twitter feed [14].

The PasseportSanté Twitter account has a total of 1072 tweets since 25 March 2009, with an average of four tweets per day. Recent health topics include video lottery dependency, the AIDS epidemic in Africa, diabetes medication Avandia, cholesterol and triglycerides, airport scanners, and many others. It has 1186 followers and is following 585 individuals and groups on Twitter, among them, the American Diabetes Association, the New England Journal of Medicine, and Fondation de l'Institut universitaire de cardiologie et de pneumologie de Québec.

The PasseportSanté Facebook site features approximately 200 posts on its wall since 9 April 2010. All posts were authored by the organization. However, many of them have several comments from a diverse group of individuals, indicating some degree of community involvement. The PasseportSanté Facebook site also has 172 notes, five photo albums from the organization, and five photos posted by others, which represents a considerable amount of content.

\section{The Heart and Stroke Foundation of Canada}

The Heart and Stroke Foundation of Canada (HSF) (http://www.heartandstroke.com/) is a national not-forprofit, volunteer-based organization dedicated to eliminating heart disease and stroke through health promotion, 
advocacy, and the advancement of research. The HSF website provides extensive informational content on heart disease and stroke, healthy living, and the organization's structure, mandate, and contact information. The design of the website is conventional, with a top menu bar, graphic icons on the right side that link to HSF events and programs, and hypertext links at the bottom of the homepage. Major events and programs are detailed on the left side of the homepage through text and images. The HSF site features two popular Web 2.0 technologies; a Twitter feed [15] and a Facebook site [16].

The HSF Twitter feed has a total of 1423 tweets, with 3078 followers, and it is following 2263 individuals and groups. The first tweet was posted on 9 June 2009, and the tweeting frequency is approximately six tweets per day. The content of the tweets covers a diverse range of topics on heart disease and stroke, including the HSF Heart Health Action Plan, CPR training and new guidelines, vegetarian pizzas, and the increased risk of heart disease for women with high job strain.

The HSF Facebook site features over 200 posts on its wall in the second half of 2010. Approximately one in three posts was authored by the organization and many of them have several comments from a diverse group of individuals. As well, many posts are authored by individuals and groups, indicating a high degree of community involvement. The HSF Facebook site also has 40 discussions and 37 YouTube videos; altogether an impressive amount of content.

Graphic icon links to these popular forms of Web 2.0 technology are prominently displayed in the centre-left text panel on the homepage of the HSF website, and there is a small "share" link at the bottom of the homepage. However, these links have not been included in the main navigation panel located at the top of the homepage where they would be more visible to site visitors. The lack of integration of these links unintentionally signifies the add-on nature of Web 2.0 technologies to this otherwise conventionally designed CHI website.

\section{Sexualityandu.ca}

Sexualityandu.ca (http://sexualityandu.ca/) is the CHI website produced by the Society of Obstetricians and Gynaecologists of Canada, a national, professional medical association. It has won awards from Chatelaine Magazine, Canadian Marketing Association, Wired Magazine's International Web Page Awards, the United Nation's World Summit Award, and the Health Improvement Institute's Aesculapius Awards of Excellence. The overall design is welcoming and features clever visual graphics, including icons of computer mice designed with sexual themes in the top right section of the homepage and large graphic icons that stream leftward representing major topics on sexuality, such as "sex over 50". Large blue graphic icons, below the streaming images, provide links to the Twitter account [17] and Facebook site [18], while three videos on Flowerplayer are presented in the bottom right corner of the homepage. However, these Web 2.0 technologies are not linked from the main navigation bar located at the top of the homepage, which may diminish their visibility to site visitors.

The sexualityandu.ca Twitter feed has a total of 109 tweets, with 958 followers, and it is following 1502 individuals and groups on Twitter. The first tweet was posted on 23 July
2009, and the tweeting frequency is approximately two tweets per day. The content of the tweets covers a diverse range of topics on sexuality, including date-rape drugs, menstruation, STIs, sexual orientation, and transgender.

The sexualityandu.ca Facebook site features approximately 25 posts on its wall. All wall posts were authored by the organization. Only two posts have comments. The frequency of posts is difficult to ascertain as it is not continuous; many posts were created either in August 2009 or May 2010. Many posts are YouTube videos produced by the organization. Clearly, this Facebook site functions exclusively to push content at site visitors, instead of fostering an interactive community of interest on human sexuality.

\section{Women's Health Matters}

Women's Health Matters (WHM) (www.womenshealth matters.ca) is the comprehensive CHI website on women's health, authored and published by Women's College Hospital, a University of Toronto-affiliated teaching hospital, and the Women's College Research Institute (WCRI). WHM features an extensive amount of informational content on women's health, primarily as text, with several navigational elements situated on the four sides of the homepage; many discussion groups (LeClub); a database of health information resources, Health A-Z; and a site search through Google search technology. WHM provides both a Twitter feed [19] and an RSS feed [20], which can be accessed from the homepage.

The WHM Twitter feed has a total of 419 tweets, with 1685 followers, and it is following 431 groups on Twitter, primarily healthcare institutions and government agencies, as well as not-for-profit health advocacy associations, including Rouge Valley Health System, the Children's Hospital of Eastern Ontario, Parkinsons Society of Canada, and Cancer Care Ontario. The first tweet was posted on 23 April 2009 , and tweeting frequency of approximately one tweet every three days. The content of the tweets covers a diverse range of women's health topics and issues, and features current research findings from Women's College Hospital.

Links to these Web 2.0 technologies are located in the left menu bar on the WHM homepage. However, they are sandwiched in between other links, which may render their presence less visible to site visitors. There do not seem to be any links to Facebook, YouTube, or other Web 2.0 technologies on the WHM website, indicating that the extension of this authoritative consumer health information website on women's health to the new world of Web 2.0 technologies is limited at this time.

\section{Caring for Kids}

Caring for Kids (http://www.caringforkids.cps.ca/) is a comprehensive CHI website on the health of children and youth developed by the Canadian Paediatrics Society (CPS), a professional medical association. The informational content is based primarily on CPS policy statements and documents developed and reviewed by the CPS public education subcommittee. The design of the site is welcoming, with images of children and parents on the homepage, as well as interesting graphical icons in the left menu bar that link to major health topics, such as immunization, safety, behavior, and pregnancy and babies. The Caring 
for Kids website has both a Twitter feed [21] and a Facebook site [22]. However, the icon links for the Twitter feed and Facebook site are buried at the bottom of the left menu bar of the homepage. Site visitors who do not scroll down to the bottom of the homepage are likely to be unaware of the existence of these Web 2.0 technologies.

The Caring for Kids Twitter feed has a total of 245 tweets, with 945 followers, and it is following 877 individuals and groups, including YATI, the youth advocacy program of the Ontario Lung Association, MS Society of Canada, the Toronto Star, and ParentsConnect (US). The first tweet was posted on 13 August 2009, and the tweeting frequency is approximately one tweet per day. Topics tweeted cover a diverse range of topics on keeping children and youth healthy, including but not limited to: Hallowe'en safety tips, rotavirus vaccination, head lice, good television habits, and over the counter cold and flu medications.

The Facebook site features healthy tips posted almost daily on the wall. The first post is dated 22 February 2010 and there are approximately 90 posts. The majority of posts were authored by the organization and have no comments. This communication practice suggests that the organization's use of Facebook is primarily as a push channel; there is little involvement from the community of parents who are the intended audience for this CHI website.

\section{The Canadian Safety Council}

The Canadian Safety Council (www.safety-council.org) is a national, not-for-profit organization on safety education for injury prevention and reduction. Its website consists overwhelmingly of static text and hypertext links. The presence of Web 2.0 technologies is limited to a Facebook site [23].

The Canadian Safety Council Facebook site seemingly functions as a unidirectional information channel insofar as all posts on the wall of this Facebook site are authored by the organization. There are approximately 30 posts on the wall, with the first post dated 21 April 2010. None of the posts have comments. Furthermore, the link from the homepage of the Canadian Safety Council website to the organization's Facebook site is not located in the main menu bar at the top of the homepage. Rather, it is found within a set of links at the bottom of the homepage, greatly diminishing its visibility to site visitors.

\section{Here to Help}

Here to Help (http://www.heretohelp.bc.ca/) is a CHI website on mental health published by the regional partnership BC Partners for Mental Health and Addictions Information. It has an RSS feed [24] on the homepage. However, the graphic icon for the RSS feed is not located in the main menu bars at the top and right sides of the homepage. Rather, it is located centre-left on the homepage, below the large graphic icons for the discussion forum, screening self-tests, and interactive tool kits, thereby reducing its visibility to site visitors. This CHI websites does not feature any other Web 2.0 technologies.

\section{AboutKidsHealth}

AboutKidsHealth (aboutkidshealth.ca) is produced by The Hospital for Sick Children (HSC) in Toronto. HSC is a large and internationally renowned University of Toronto-affiliated teaching hospital. The content on AboutKidsHealth is written by professional writers and editors, in collaboration with HSC clinicians, and is assessed by an Editorial Review Board. The informational content on this paediatric CHI website is predominantly textual, with the judicious use of static images and several video clips. There is an animated interactive atlas of child anatomy and physiology, "How the Body Works". While AboutKidsHealth does not feature Web 2.0 technologies such as Twitter and Facebook, content webpages do have a "Share" link, enabling readers to send the content to Web 2.0 social networking sites or to bookmark it using a social bookmarking utility.

\section{The Dietitians of Canada}

The Dietitians of Canada (http://www.dietitians.ca/) is the national professional association for dietitians in Canada. Its mission is to advance the health of Canadians through food and nutrition. The Dietitians of Canada website provides informational content on nutrition on the Your Health section (http://www.dietitians.ca/Your-Health/Assess-Yourself. aspx) of the site, primarily as text with static images, as well as several interactive tools, such as the body mass index calculator. The "Find A Dietitian" feature enables users to search for a dietitian in a specific region. While this CHI website is well designed and offers useful information, it does not feature any Web 2.0 technologies.

\section{Discussion}

Three of the top $10 \mathrm{CHI}$ websites in Canada are leaders in the adoption of Web 2.0 technologies: the Canadian Cancer Society, PasseportSanté, and the Heart and Stroke Foundation of Canada. All three have a Twitter feed with thousands of tweets, a Facebook site with at least 100 wall posts, a YouTube channel or streaming video, and a "Share" button with icon links to many social sites such as Bebo and Delicious. Noteworthy is the observation that these CHI websites are all published by not-for-profit groups.

Reputable Canadian CHI websites that provide a moderate number of Web 2.0 technologies include sexualityandu.ca, Women's Health Matters, and Caring for Kids. All three have Twitter accounts with a minimum of 100 tweets. Two of the three have Facebook sites, while one has an RSS feed. Furthermore, two of the three are published by professional physician associations, while one is published by a healthcare institution.

Four of the top 10 Canadian CHI websites have either little (Canadian Safety Council, Here to Help) or no (AboutKidsHealth, Dietitians of Canada) Web 2.0 presence. It is not clear why these CHI websites offer so little in the form of Web 2.0 technologies at present or whether this will change in the near future.

Another measurement for determining the extent to which Web 2.0 technologies are embedded in these Canadian CHI websites is the Twitter feed date range. Examining the entire list of tweets in the Twitter feeds of these established CHI websites reveals their recent nature; the first tweets date back to 2009. This indicates that the adoption of Web 2.0 technologies by conventional CHI websites is a recent endeavour. 
Table 1. Web 2.0 technologies on the top 10 Canadian consumer health information (CHI) websites.

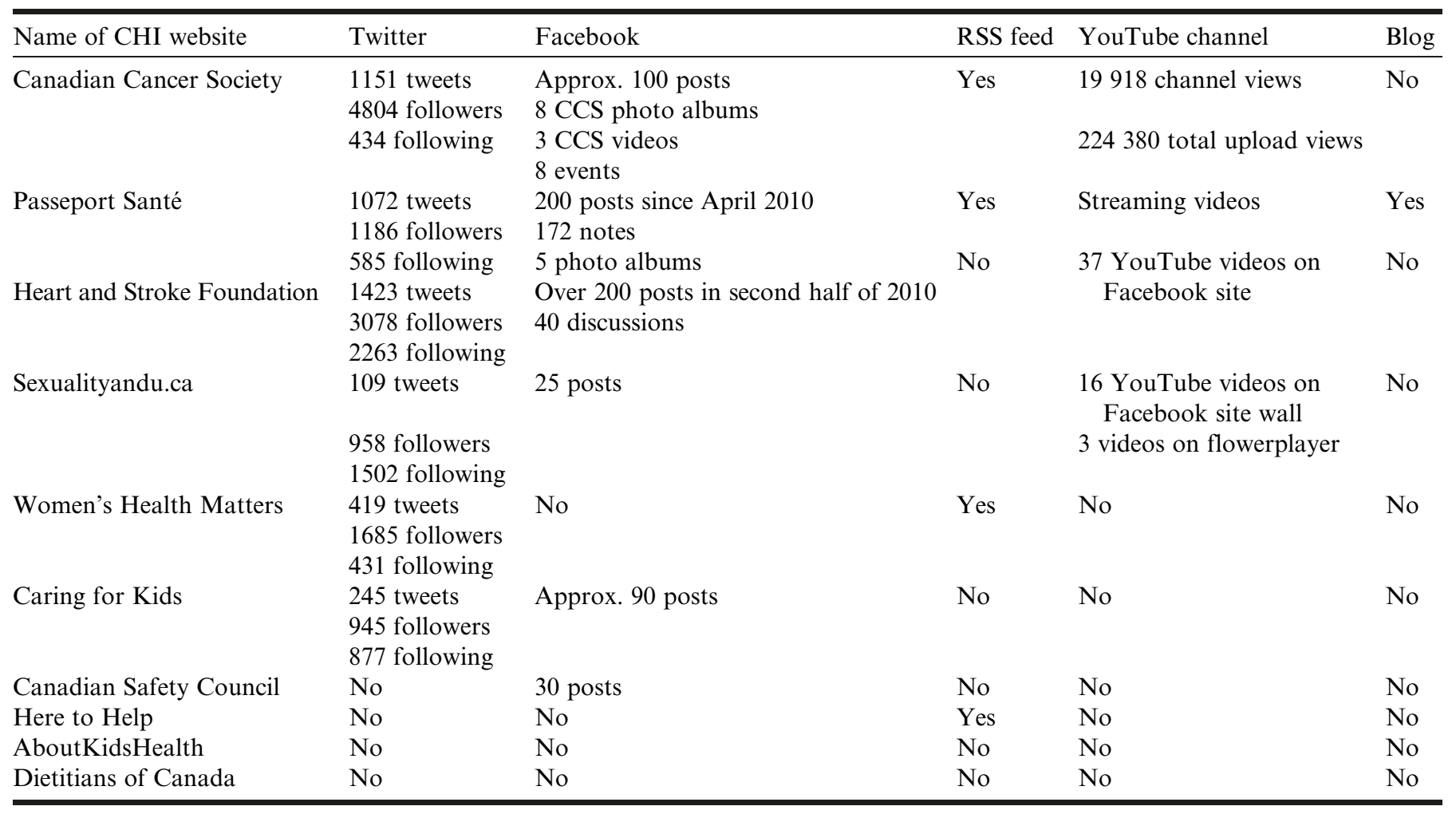

Furthermore, an indicator of the pervasiveness of Web 2.0 technologies on $\mathrm{CHI}$ websites is the amount of content and interactivity on their Facebook sites. Apart from the number of posts on the wall, the authorship of the posts and the number of comments serve to demonstrate the extent of community involvement. The three Canadian CHI websites with the greatest number of Web 2.0 technologies are also leaders in interactivity on Facebook, with posts authored by individuals and groups, which are also commented upon.

As 2010 drew to a close, the inclusion of Web 2.0 technologies on the top 10 Canadian CHI websites was found to be highly variable. A detailed list of the types of Web 2.0 technologies deployed on reputable Canadian CHI websites is provided in Table 1. While 3 of 10 sites demonstrate considerable use of the two most common Web 2.0 technologies, Twitter and Facebook, and another 3 show substantial use of Twitter, the 4 remaining sites do not make much, if any, use of popular Web 2.0 technologies. None of these sites incorporated links to their Web 2.0 sites in their main navigation bar. Furthermore, many Web 2.0 technologies are deployed infrequently, if at all, on any of these reputable CHI websites, such as blogs, RSS feeds, podcasts, and folksonomies. Clearly, the use of Web 2.0 technologies on the top 10 Canadian CHI websites is in its infancy.

\section{References}

1. Berners-Lee T, Fischetti M. Weaving the Web: the original design and ultimate destiny of the world wide web. San Francisco: Harper Collins; 2000.
2. O'Reilly T. What Is Web 2.0: Design Patterns and Business Models for the Next Generation of Software [Internet]. 2005. O'Reilly Media. [accessed 25 Nov 2010]. Available from: http:// oreilly.com/pub/a/web2/archive/what-is-web-20.html?page $=1$.

3. Consumer Health Information Providers Interest Group. Top 10 Canadian consumer health websites [Internet]. 2010. [accessed 25 Nov 2010]. Available from: http://www.chla-absc. ca/chipig/Events/CHLA2010poster.pdf.

4. Canadian Cancer Society. Other Ways to Stay Connected [Internet]. [accessed 25 Nov 2010]. Available from: http://www.cancer. $\mathrm{ca} /$ Canada-wide/About $\% 20$ us/Other $\% 20$ ways $\% 20$ to $\% 20$ stay $\%$ 20connected.aspx?sc_lang=en.

5. Canadian Cancer Society. Cdn Cancer Society (cancersociety) on Twitter [Internet]. [accessed 25 Nov 2010]. Available from: http://twitter.com/cancersociety.

6. Canadian Cancer Society. Canadian Cancer Society | Facebook [Internet]. [accessed 25 Nov 2010]. Available from: http://www.facebook.com/CanadianCancerSociety.

7. Canadian Cancer Society. YouTube - CDNCancerSociety's Channel [Internet]. [accessed 25 Nov 2010]. Available from: http://www.youtube.com/cdncancersociety/.

8. Canadian Cancer Society. Media releases [Internet]. [accessed 25 Nov 2010]. Available from: http://www.cancer.ca/ccs/rss/cw/ media_en.xml.

9. Canadian Cancer Society. What are feeds [Internet]. [accessed 25 Nov 2010]. Available from: http://www.cancer.ca/Canada-wide/ About $\% 20$ us/Media $\% 20$ centre/CW-Media $\% 20$ releases/What $\%$ 20 are $\% 20$ feeds.aspx?sc_lang $=$ en. 
10. Canadian Cancer Society. iGoogle. Get Canadian Cancer Society - Media releases on your Google homepage [Internet]. [accessed 25 Nov 2010]. Available from: http://www.google.ca/ ig/adde?hl=en\&moduleurl=www.cancer.ca/ccs/rss/cw/media_ en.xml\&source $=$ imag.

11. Totalmédia inc., une filiale de la Fondation Lucie et André Chagnon. Comment recevoir les nouvelles et les blogues de PasseportSanté.net par fil RSS [Internet]. [accessed 25 Nov 2010]. Available from: http://www.passeportsante.net/fr/P/P/ RSS_Abonner.aspx.

12. Totalmédia inc., une filiale de la Fondation Lucie et André Chagnon. Blogues [Internet]. [accessed 25 Nov 2010]. Available from: http://blogue.passeportsante.net/.

13. Totalmédia inc., une filiale de la Fondation Lucie et André Chagnon. PasseportSanté | Facebook [Internet]. [accessed 25 Nov 2010]. Available from: http://www.facebook.com/PasseportSante. net.

14. PasseportSanté. Martin LaSalle (PasseportSante) on Twitter [Internet]. [accessed 25 Nov 2010]. Available from: http:// twitter.com/PasseportSante.

15. Heart and Stroke Foundation. Heart and Stroke FDN (TheHSF) on Twitter [Internet]. [accessed 25 Nov 2010]. Available from: http://twitter.com/TheHSF.

16. Heart and Stroke Foundation. Heart and Stroke Foundation | Facebook [Internet]. [accessed 25 Nov 2010]. Available from: http://www.facebook.com/heartandstroke.

17. Society of Obstetricians and Gynaecologists of Canada. Seuxalityandu.ca (sexualityandu) on Twitter [Internet]. [accessed 25 Nov 2010]. Available from: http://twitter.com/sexualityandu.
18. Society of Obstetricians and Gynaecologists of Canada. SexualityandU | Facebook [Internet]. [accessed 25 Nov 2010]. Available from: http://www.facebook.com/SexAndU?v=wall\&ref =sgm.

19. Women's College Hospital and Women's College Research Institute. Women's Health Matters (womenshealthweb) on Twitter [Internet]. [accessed 25 Nov 2010]. Available from: http://twitter.com/womenshealthweb.

20. Women's College Hospital and Women's College Research Institute. News from womenshealthmatters.ca [Internet]. [accessed 25 Nov 2010]. Available from: http://feeds.feedburner.com/ womenshealthmatters/lmSl.

21. Canadian Paediatric Society. Caring for kids (Caringforkids) on Twitter [Internet]. [accessed 25 Nov 2010]. Available from: http://twitter.com/CaringforKids.

22. Canadian Paediatric Society. Caring for kids | Facebook [Internet]. [accessed 25 Nov 2010]; Available from: http://www. facebook.com/caringforkids.cps.ca.

23. Canadian Safety Council. Canadian Safety Council | Facebook [Internet]. [accessed 25 Nov 2010]. Available from: http://www.facebook.com/canada.safety.

24. Anxiety Disorders Association of BC, BC Schizophrenia Society, Canadian Mental Health Association, BC Division Centre for Addictions Research of BC, FORCE Society for Kids' Mental Health, Jessie's Legacy Program, Family Services of the North Shore and Mood Disorders Association of BC. HereToHelp News Feed [Internet]. [accessed 25 Nov 2010]. Available from: http://www.heretohelp.bc.ca/news/ feed/. 